\title{
Secondary spontaneous pneumothorax in patients with sarcoma treated with Pazopanib, a case control study
}

\author{
Bruce Sabath ${ }^{1}$, Hasan A Muhammad ${ }^{1}$, Amulya Balagani ${ }^{1}$, David E Ost ${ }^{1}$, Erik Vakil', Tahreem Ahmed²,
} Macarena R Vial $^{3}$ and Horiana B Grosu ${ }^{1 *}$ (D)

\begin{abstract}
Background: The tyrosine kinase inhibitor pazopanib is used for treatment of sarcoma. Recent studies have suggested that the use of pazopanib may lead to the development of pneumothorax, an unexpected adverse effect in patients with sarcoma metastatic to the chest.
\end{abstract}

Methods: We conducted a retrospective case control study of patients with sarcoma with metastases to the chest with pneumothorax (cases) and without pneumothorax (controls). The control population was selected from tumor registry in a 1:4 (cases to controls) ratio. The primary outcome of interest was the association between pazopanib and pneumothorax risk in patients with sarcoma metastatic to the chest. Secondary objective was to evaluate risk factors for pneumothorax.

Results: We identified 41 cases and 164 controls. Using purposeful selection method the odds of developing pneumothorax while being on pazopanib was not significant in univariate $(p=.06)$ and multivariable analysis $(p=.342)$. On univariate analysis risk factors of pneumothorax in patients with sarcoma were age, male sex, African American race, the presence of cavitary lung nodules/masses, and the presence of pleural-based nodules/masses. On multivariate analysis, only the presence of cavitary lung nodules/masses $(P<.001)$ and the presence of pleural-based nodules/masses $(P<.001)$ remained as risk factors for developing pneumothorax.

Conclusion: Pazopanib does not increase the risk of pneumothorax in patients with sarcoma and evidence of metastatic disease to the chest. Presence of cavitary lung nodules/masses and the presence of pleural-based nodules/masses were found to be risk factors for pneumothorax.

\section{Background}

Nearly all underlying lung disorders can be associated with secondary spontaneous pneumothorax (SSP), nonetheless, it is most commonly associated with emphysema, cystic fibrosis, infections, and malignancy [1]. Several studies have reported an association between metastatic osteogenic or soft tissue sarcomas with pneumothorax, especially in the setting of cytotoxic chemotherapy or radiotherapy $[1,2]$. To date, however, except for a limited number of case reports and small case series, little has been published to substantiate that

\footnotetext{
* Correspondence: hbgrosu@mdanderson.org

${ }^{1}$ Department of Pulmonary Medicine, Unit 1462, The University of Texas MD

Anderson Cancer Center, 1515 Holcombe Blvd, Houston, TX 77030, USA

Full list of author information is available at the end of the article
}

the incidence of SSP in soft tissue sarcoma patients is higher than that in patients with other tumors [3-12].

Pazopanib, a multitarget tyrosine kinase inhibitor, was approved in 2012 for the treatment of soft tissue sarcoma on the basis of evidence of improved progression-free survival in advanced disease [13]. Since the introduction of pazopanib, however, pneumothorax has been reported as an unexpected adverse event. A recent case series found the incidence of pneumothorax to be $14 \%$, much higher than previous data had suggested [14]. Of interest, other studies of pazopanib prescribed for non-sarcoma cancers did not report pneumothorax as an adverse event [15-17]. Therefore, higher quality evidence is needed to investigate the question on whether pazopanib is truly a risk factor.

(c) The Author(s). 2018 Open Access This article is distributed under the terms of the Creative Commons Attribution 4.0 International License (http://creativecommons.org/licenses/by/4.0/), which permits unrestricted use, distribution, and reproduction in any medium, provided you give appropriate credit to the original author(s) and the source, provide a link to the Creative Commons license, and indicate if changes were made. The Creative Commons Public Domain Dedication waiver (http://creativecommons.org/publicdomain/zero/1.0/) applies to the data made available in this article, unless otherwise stated. 
The primary outcome of our study was an assessment of the association between pazopanib and the occurrence of SSP in patients with sarcoma. We hypothesized that pazopanib is associated with a higher risk of SSP in patients with evidence of metastatic sarcoma to the lungs. Our secondary objective was to evaluate risk factors for SSP in patients with sarcoma.

\section{Methods}

\section{Study design}

This retrospective case control study was designed to obtain preliminary data about the association between pazopanib and pneumothorax in patients with sarcoma metastatic to the lung. The University of Texas MD Anderson Cancer Center Institutional Review Board approved this study (IRB protocol number PA15-0761).

\section{Study population}

All patients were 16 years of age or older and presented to our institution with a secondary spontaneous pneumothorax between January 1, 2005, and May 31, 2017. Cases were those patients with sarcoma and evidence of metastatic disease to the chest with pneumothorax. These were identified with use of the following International Classification of Diseases (ICD) diagnostic codes: ICD9 (512.89, 512.83, 512.81, 512.82, and 512.0) and ICD10 (J93, J93.9, J93.83, J93.81, J93.12, and J93.11) (Fig. 1). Controls were patients with sarcoma and evidence of metastatic disease to the chest but without pneumothorax. We identified controls from a sarcoma tumor registry at a ratio of 1:4 (cases to controls). We used density sampling to select controls. Incidence density sampling was used as controls were selected from the persons at risk (those with sarcoma) who survived at least as long as the index cases.

\section{Definitions}

Secondary spontaneous pneumothorax was defined as a pneumothorax in the absence of trauma or an iatrogenic cause in a patient with evidence of metastatic disease to the chest (lung, pleura) regardless of the presence of emphysema or other risk factors for pneumothorax.

Evidence of metastatic disease to the chest was defined as biopsy- or cytology-proven metastatic disease, or multiple nodules/masses in a typical radiological pattern (by PET or CT) with findings sufficiently suggestive that the patient was deemed by his/her health care providers to have metastatic disease to the chest.

\section{Statistical considerations}

For demographic and clinical characteristics, we used means and standard deviation to describe continuous variables distributed normally. We used medians and interquartile ranges (25-75\%) for non-normally distributed data. We used frequencies for categorical data.

To determine whether pazopanib is associated with SSP in patients with sarcoma we used purposeful selection variables in logistic regression [18]. We used this method to improve the chances of retaining meaningful confounders, and we looked at the association of the exposure variable (pazopanib) with the other covariates and only included those variables that are associated with the exposure of interest (pazopanib) [18]. The purposeful selection process began with univariate analysis of each variable. Any variable with an arbitrary $p$-value cut-off point of 0.15 or confounding level of $15 \%$ was included in the multivariate model [18].

In a secondary analysis to determine the risk factors for SSP in patients with sarcoma we used univariate and multivariate logistic regression, with the outcome variable being SSP. Variables with a $P$-value of $<.20$ on univariate analysis were considered candidate variables

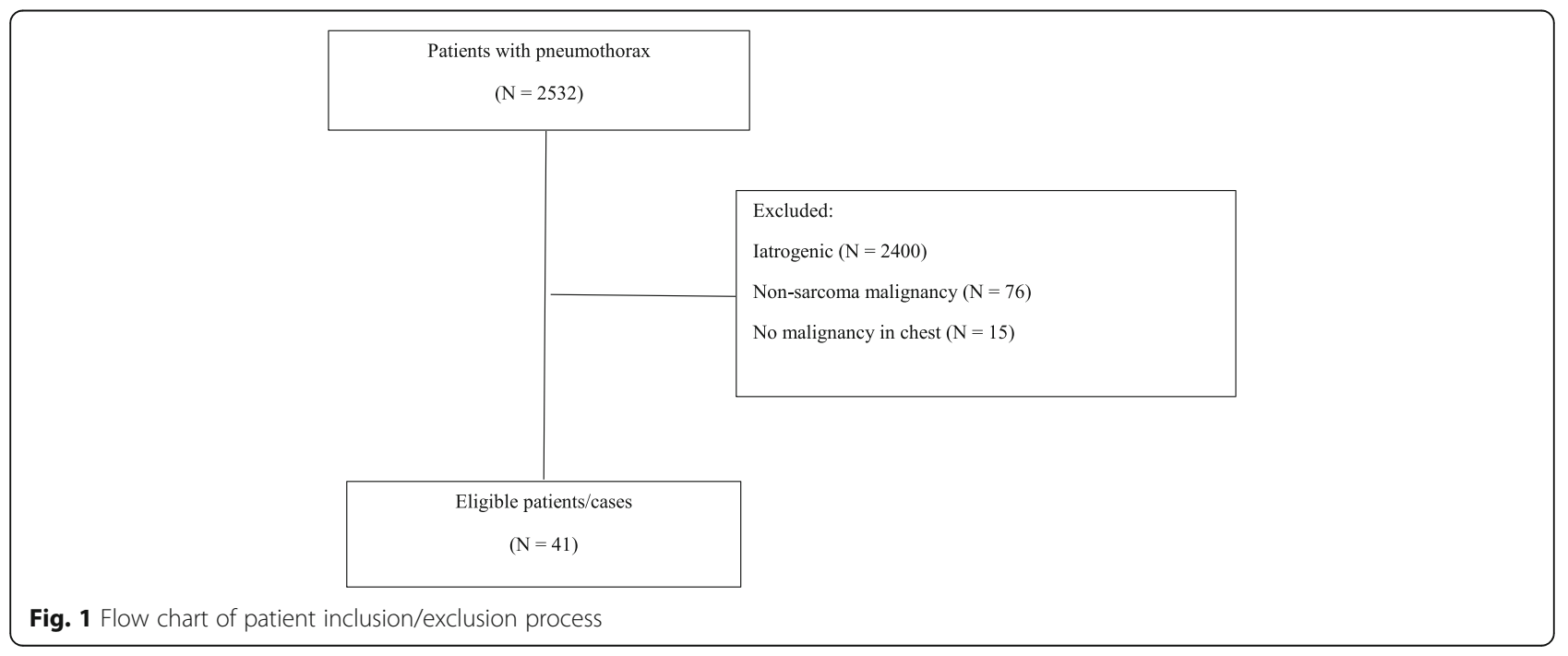


for the multivariate regression model. Backward selection, with a $P$-value of $<.05$ to stay in the model, was used to arrive at a parsimonious multivariable model.

We accepted a two-tailed $P$-value of $<.05$ as statistically significant for all analyses. We used Intercooled Stata 13 software (College Station, TX) for data analysis.

\section{Results}

We identified 2532 patients with a diagnosis of pneumothorax who were evaluated in our institution during the specified time period. Of these patients, 2400 patients had an iatrogenic pneumothorax, and 15 did not have metastatic disease to the chest; these were excluded. The remaining 117 patients presented with a secondary spontaneous pneumothorax associated with metastatic disease to the chest, among whom 41 had sarcoma. We identified 164 controls from institutional tumor registry. Patient's characteristics by group was provided in Table 1 .

The median dose of pazopanib in patients who developed pneumothorax was $800 \mathrm{mg}$ (range $400 \mathrm{mg}$ to $800 \mathrm{mg}$ ) and in those who did not develop pneumothorax was $800 \mathrm{mg}$ (range $400 \mathrm{mg}$ to $800 \mathrm{mg}$ ). This was not statistically significantly different $(p=0.695)$.

The median time on pazopanib in patients who developed pneumothorax was 96 days (range 77-1109) and in those who did not develop pneumothorax was 171 days (range 51to 584 days). This was not statistically significantly different $(p=0.316)$.

Patient's characteristics by exposure status with measure of the association are presented in Table 2. For the primary outcome of whether pazopanib is associated with SSP only risk factors that are associated with the confounder were included the model using purposeful selection [18]. In the univariate model the odds of developing pneumothorax while being on pazopanib was not significant $[\mathrm{OR}=2.4095 \% \mathrm{CI}(.943$ to 6.147$) p=.06]$. In the multivariate model the odds of developing pneumothorax while being on pazopanib was not significant [OR $=1.7195 \% \mathrm{CI}(.562$ to 5.239$) p=0.342]$.
Table 1 Patient characteristics

\begin{tabular}{|c|c|c|}
\hline Characteristics & $\begin{array}{l}\text { Cases/pneumothorax } \\
N=41\end{array}$ & $\begin{array}{l}\text { Controls/no pneumothorax } \\
N=164\end{array}$ \\
\hline \multicolumn{3}{|l|}{ Age, years } \\
\hline Mean + SD & $37.92+16.88$ & $44.8+19.5$ \\
\hline \multicolumn{3}{|l|}{ Gender } \\
\hline Male & $29(70 \%)$ & $77(47 \%)$ \\
\hline Female & $12(30 \%)$ & $87(53 \%)$ \\
\hline \multicolumn{3}{|l|}{ Race } \\
\hline White & $21(51 \%)$ & $119(73 \%)$ \\
\hline $\begin{array}{l}\text { African } \\
\text { American }\end{array}$ & $10(24 \%)$ & $14(9 \%)$ \\
\hline $\begin{array}{l}\text { Hispanic/ } \\
\text { other }\end{array}$ & $10(24 \%)$ & $31(19 \%)$ \\
\hline \multicolumn{3}{|c|}{ Cavitary lung nodules/masses } \\
\hline Yes & $26(63 \%)$ & $36(22 \%)$ \\
\hline No & $15(37 \%)$ & $128(78 \%)$ \\
\hline \multicolumn{3}{|c|}{ Pleural-based lung nodules/masses } \\
\hline Yes & $35(85 \%)$ & $62(38 \%)$ \\
\hline No & $6(15 \%)$ & $102(62 \%)$ \\
\hline \multicolumn{3}{|c|}{ Emphysema present } \\
\hline Yes & $2(5 \%)$ & $1(1 \%)$ \\
\hline No & $39(95 \%)$ & $163(99 \%)$ \\
\hline \multicolumn{3}{|c|}{ Prior radiation to the chest } \\
\hline Yes & $1(2 \%)$ & $2(2 \%)$ \\
\hline No & 40 (98\%) & $162(98 \%)$ \\
\hline \multicolumn{3}{|c|}{ Patient was receiving pazopanib } \\
\hline Yes & $8(19 \%)$ & $15(9 \%)$ \\
\hline No & $33(81 \%)$ & $149(91 \%)$ \\
\hline
\end{tabular}

Table 2 Patient characteristics by exposure status

\begin{tabular}{|c|c|c|c|}
\hline Characteristics & $\begin{array}{l}\text { Patient was } \\
\text { on pazopanib } \\
N=23\end{array}$ & $\begin{array}{l}\text { Patient was not } \\
\text { on pazopanib } \\
N=182\end{array}$ & $p$ \\
\hline \multicolumn{4}{|l|}{ Age, years } \\
\hline Mean + SD & $40.63+3.23$ & 43. $81+1.45$ & 0.456 \\
\hline \multicolumn{4}{|l|}{ Gender } \\
\hline Male & $11(48 \%)$ & $95(52 \%)$ & \\
\hline Female & $12(52 \%)$ & $87(48 \%)$ & 0.693 \\
\hline \multicolumn{4}{|l|}{ Race } \\
\hline White & $18(78 \%)$ & $122(67 \%)$ & \\
\hline African American & $3(13 \%)$ & $21(12 \%)$ & \\
\hline Hispanic/other & $2(9 \%)$ & $39(21 \%)$ & 0.355 \\
\hline \multicolumn{4}{|c|}{ Cavitary lung nodules/masses } \\
\hline Yes & $10(43 \%)$ & $52(29 \%)$ & \\
\hline No & $13(57 \%)$ & $130(71 \%)$ & 0.142 \\
\hline \multicolumn{4}{|c|}{ Pleural-based lung nodules/masses } \\
\hline Yes & $14(61 \%)$ & $83(46 \%)$ & \\
\hline No & $9(39 \%)$ & $99(54 \%)$ & 0.167 \\
\hline \multicolumn{4}{|l|}{ Emphysema present } \\
\hline Yes & $0(0 \%)$ & $3(2 \%)$ & \\
\hline No & $23(100 \%)$ & $179(98 \%)$ & 0.535 \\
\hline \multicolumn{4}{|c|}{ Prior radiation to the chest } \\
\hline Yes & $0(0 \%)$ & $3(2 \%)$ & \\
\hline No & $23(100 \%)$ & $179(98 \%)$ & 0.535 \\
\hline \multicolumn{4}{|c|}{ Patient developed pneumothorax } \\
\hline Yes & $8(35 \%)$ & $33(18 \%)$ & \\
\hline No & 15 (65\%) & 149 (82\%) & 0.060 \\
\hline
\end{tabular}


For the secondary objective of determining the risk factors for SSP on univariate analysis, age, male sex, African American race (compared with White race), the presence of cavitary lung nodules/masses, and the presence of pleural-based nodules/masses significantly impacted the odds of developing pneumothorax (Table 2). The odds of developing pneumothorax while being treated with pazopanib did not reach statistical significance on univariate analysis $(P=.06)$. In the multivariate model, only the presence of cavitary lung nodules/ masses $(P<.001)$ and the presence of pleural-based nodules/masses $(P<.001)$ remained as risk factors for developing pneumothorax (Table 3 ).

\section{Discussion}

Soft tissue sarcomas metastasize with sizeable frequency, and in nearly one-fourth of patients, the disease metastasizes to the lungs, specifically [19]. With regard to secondary spontaneous pneumothorax as a further complication, several studies have been documented over the years $[3-5,7,8]$; recently, however, the incidence of SSP increased with the introduction of pazopanib for patients with sarcoma metastatic to the lungs [9, 10, 14, 20-23]. If there is such an association, this would be problematic because pazopanib is an attractive therapeutic option, given data showing improved prognosis in advanced disease [13]. Our study addressed this question. We showed that in patients with sarcoma and lung metastasis, pazopanib does not increase the odds of developing pneumothorax.

To our knowledge, this is the largest study of sarcoma patients with lung metastases and pneumothorax. The previous literature included case reports and small series, but none used methods to assess for risk factors of statistical significance as our investigation did. We found 41 cases of sarcoma metastatic to the lungs with pneumothorax and compared them with 164 controls without pneumothorax. The dose and the duration on pazopanib was not different on those patients who developed pneumothorax vs those who did not develop pneumothorax while on pazopanib. We were unable to find an association with pazopanib to explain the difference between these two groups. Notably, the PALETTE trial, which led to the approval of pazopanib for use in sarcoma, detected only a $2 \%$ pneumothorax rate despite a large sample of sarcoma patients [13].

Similar to our analysis, other analyses have found an association of spontaneous pneumothorax with cavitary and pleural-based lung lesions in metastatic sarcoma [5]. This may provide some insight into the mechanism underlying the development of pneumothorax, which has yet to be clearly defined in this population. It has been suggested that cytotoxic agents may induce necrosis and cavitation of lung nodules, thereby increasing risk of rupture and the development of pneumothorax [24]. Indeed, aside from pazopanib, other chemotherapeutic agents have been reported in association with pneumothorax in patients with advanced sarcoma $[3-5,7,8]$.

A review of the literature describing 153 cases of spontaneous pneumothorax in patients with sarcoma noted that the drugs used most commonly before occurrence of pneumothorax included doxorubicin (49.1\%), cyclophosphamide (37.6\%), and vincristine (35.8\%) [5]. Despite this theory, two-thirds of patients in this series developed pneumothorax before initiation of any treatment. Similarly, of the 41 study cases from our cohort, 26 (63\%) had evidence of cavitation; among this group, only 6 (23\%) developed cavitation while receiving pazopanib and 20 (77\%) developed cavitation without receiving pazopanib. As such, it is likely the nature of the disease itself-including specific

Table 3 Risk factors for developing pneumothorax in patients with sarcoma and metastatic disease to the chest

\begin{tabular}{|c|c|c|c|c|c|c|c|c|}
\hline \multirow[t]{2}{*}{ Covariate } & \multicolumn{4}{|c|}{ Univariate model } & \multicolumn{4}{|c|}{ Multivariate model } \\
\hline & $\mathrm{OR}$ & $95 \% \mathrm{Cl}$ & & $P$-value & $\mathrm{OR}$ & $95 \% \mathrm{Cl}$ & & $P$-value \\
\hline Age & 0.981 & 0.963 & 0.999 & .041 & & & & \\
\hline Male & 2.73 & 1.303 & 5.719 & .008 & & & & \\
\hline \multicolumn{9}{|l|}{ Race } \\
\hline White & 1.000 & & & & & & & \\
\hline African American & 4.047 & 1.589 & 10.307 & .003 & & & & \\
\hline Hispanic/Other & 1.827 & 0.780 & 1.278 & .164 & & & & \\
\hline Cavitary lung nodule/mass & 6.162 & 2.954 & 12.855 & $<.001$ & 7.024 & 3.023 & 16.315 & $<.001$ \\
\hline Pleural base lung nodule/mass & 9.596 & 3.817 & 24.123 & $<.001$ & 10.390 & 3.824 & 28.230 & $<.001$ \\
\hline Emphysema present & 8.358 & 0.739 & 94.54 & .086 & & & & \\
\hline Prior radiation to the chest present & 2.025 & 0.179 & 22.893 & .569 & & & & \\
\hline Patient was receiving pazopanib & 2.408 & 0.943 & 6.147 & .06 & & & & \\
\hline
\end{tabular}

$\mathrm{Cl}=$ confidence interval, $O R=$ odds ratio 
characteristics of lung metastases (e.g., cavitation, pleural location)-that increases the risk of pneumothorax rather than any agent.

Pazopanib is an antiangiogenic agent that targets the vascular endothelial growth factor receptor that in theory has the potential of causing cavitation of lung lesions and increased risk of pneumothorax $[13,25,26]$. However, our data do not support this theory since among our cases, 26 patients (63\%) had evidence of cavitation, 6 (23\%) of whom developed cavitation while receiving pazopanib and 20 (77\%) of whom developed cavitation without receiving pazopanib. We believe that it is likely the nature of the disease, not the pazopanib that increases the risk of pneumothorax in patients with sarcoma and evidence of metastatic disease to the chest. This is also supported by the fact that other tumor types, such as renal cell or ovarian carcinomas, on pazopanib treatment did not report pneumothorax as a complication $[27,28]$.

We recognize several limitations to our study including those inherent to case control analyses that are subject to selection bias. The information about exposure is subject to observation bias as well. Moreover, our patients are not directly comparable to those without evidence of metastatic disease to the chest or of a different tumor type so our data cannot be generalizable to other patient populations. In addition, the small sample size may be responsible for failure for find a difference between the pneumothorax and pazopanib. We used purposeful selection method as, in addition to significant covariates, this methodology retains important confounding variables, with an attempt to develop a slightly richer model [18].

\section{Conclusion}

On the basis of our findings we conclude that pazopanib does not increase the pneumothorax risk in patients with sarcoma and evidence of metastatic disease to the chest however the study may have been underpowered to detect a difference. Other factors, however, such as the presence of cavitary or pleural-based nodules/ masses, were found to be associated with increased risk of pneumothorax in this patient population.

\section{Availability of data and materials}

The datasets used and/or analyzed during the current study are available from the corresponding author on reasonable request.

\section{Authors' contributions}

HG was principal investigator and was responsible for study design, analysis, management, writing, and editing. $\mathrm{HG}, \mathrm{BS}, \mathrm{DO}$ was responsible for study oversight, analysis and writing. $\mathrm{HM}, \mathrm{AB}, \mathrm{EV}, \mathrm{TA}, \mathrm{MV}$ performed data collection, data entry, and corrections. All authors participated in reviewing and editing the manuscript. All authors read and approved the final manuscript.
Ethics approval and consent to participate

The University of Texas MD Anderson Cancer Center Institutional Review Board approved this study and informed consent was waived by the Institutional Review Board 4 with the protocol number PA15-0761.

\section{Consent for publication}

Not applicable.

Competing interests

The authors declare that they have no competing interests.

\section{Publisher's Note}

Springer Nature remains neutral with regard to jurisdictional claims in published maps and institutional affiliations.

\section{Author details}

${ }^{1}$ Department of Pulmonary Medicine, Unit 1462, The University of Texas MD Anderson Cancer Center, 1515 Holcombe Blvd, Houston, TX 77030, USA. ${ }^{2}$ Thoracic Surgery, The University of Texas MD Anderson Cancer Center, Houston, TX, USA. ${ }^{3}$ Universidad del Desarrollo Clinica Alemana de Santiago, Santiago, Chile.

Received: 1 June 2018 Accepted: 26 September 2018

Published online: 01 October 2018

References

1. Wright FW. Spontaneous pneumothorax and pulmonary malignant disease--a syndrome sometimes associated with cavitating tumours. Report of nine new cases, four with metastases and five with primary bronchial tumours. Clin Radiol. 1976:27:211-22.

2. Fayda M, Kebudi R, Dizdar $Y$, et al. Spontaneous pneumothorax in children with osteosarcoma: report of three cases and review of the literature. Acta Chir Belg. 2012;112:378-81.

3. Fenlon HM, Carney D, Breatnach E. Case report: bilateral recurrent tension pneumothorax complicating combination chemotherapy for soft tissue sarcoma. Clin Radiol. 1996:51:302-4.

4. Upadya A, Amoateng-Adjepong Y, Haddad RG. Recurrent bilateral spontaneous pneumothorax complicating chemotherapy for metastatic sarcoma. South Med J. 2003;96:821-3.

5. Hoag JB, Sherman M, Fasihuddin Q, Lund ME. A comprehensive review of spontaneous pneumothorax complicating sarcoma. Chest. 2010;138:510-8.

6. Han SS, Diznoff B, Renzi EM. Spontaneous pneumothorax as a complication of pulmonary metastatic sarcoma. A report of three cases. Del Med J. 1976:48:139-44

7. Mezghani S, Benzarti M, Njima H, et al. Recurrent spontaneous pneumothorax complicating osteosarcoma pulmonary metastasis. Rev Pneumol Clin. 2005:61:50-2.

8. Barnoud R, Collardeau-Frachon S, de la Roche E, et al. [Lung metastases of epithelioid sarcoma revealed by bilateral spontaneous pneumothorax: a pathological diagnosis]. Ann Pathol 2010;30:139-142.

9. Jeon SY, Yhim HY, Lee NR. Epithelioid sarcoma with spontaneous pneumothorax and massive pleural effusion. Korean J Intern Med. 2016:31:191-3.

10. Petrosyan A, Bergeron P. Extensive surgical treatment of primary pulmonary synovial sarcoma after recurrent pneumothorax. Ann Thorac Surg. 2015:100:1893-5.

11. Naomi A, Oyamatsu Y, Narita K, Nakayama M, Maeda M. Pneumothorax secondary to pulmonary metastasis of Angiosarcoma of the scalp;report of a case. Kyobu Geka. 2015;68:551-5.

12. Clark MA, Fisher C, Judson I, Thomas JM. Soft-tissue sarcomas in adults. N Engl J Med. 2005;353:701-11.

13. van der Graaf WT, Blay JY, Chawla SP, et al. Pazopanib for metastatic softtissue sarcoma (PALETTE): a randomised, double-blind, placebo-controlled phase 3 trial. Lancet (London England). 2012;379:1879-86.

14. Verschoor AJ, Gelderblom H. Pneumothorax as adverse event in patients with lung metastases of soft tissue sarcoma treated with pazopanib: a single reference Centre case series. Clin Sarcoma Res. 2014;4:14.

15. Friedlander M, Hancock KC, Rischin D, et al. A phase II, open-label study evaluating pazopanib in patients with recurrent ovarian cancer. Gynecol Oncol. 2010;119:32-7. 
16. Necchi A, Mariani L, Zaffaroni N, et al. Pazopanib in advanced and platinumresistant urothelial cancer: an open-label, single group, phase 2 trial. Lancet Oncol. 2012;13:810-6.

17. Sternberg CN, Hawkins RE, Wagstaff J, et al. A randomised, double-blind phase III study of pazopanib in patients with advanced and/or metastatic renal cell carcinoma: final overall survival results and safety update. Eur J Cancer. 2013;49:1287-96.

18. Bursac Z, Gauss CH, Williams DK, Hosmer DW. Purposeful selection of variables in logistic regression. Source Code for Biol Med. 2008;3:17.

19. Billingsley $K G$, Burt ME, Jara E, et al. Pulmonary metastases from soft tissue sarcoma: analysis of patterns of diseases and postmetastasis survival. Ann Surg. 1999;229:602-10 discussion 10-2.

20. Celik B, Surucu ZP, Yilmaz V, Celik HK. A case report of secondary simultaneous bilateral pneumothorax due to Pazopanib treatment. Turkish thoracic J. 2018:19:49-51.

21. Nakano A, Kato M, Watanabe T, et al. OK-432 chemical pleurodesis for the treatment of persistent chylothorax. Hepato-Gastroenterology. 1994;41:568-70.

22. Nakano K, Inagaki L, Tomomatsu J, et al. Incidence of pneumothorax in advanced and/or metastatic soft tissue sarcoma patients during pazopanib treatment. Clin Oncol (R Coll Radiol). 2014;26:357.

23. Ezzeddine F, Jalal S. Spontaneous Pneumothoraces and Hemothoraces in sarcomas. Cureus. 2017:9:e1905.

24. Interiano RB, McCarville MB, Wu J, Davidoff AM, Sandoval J, Navid F. Pneumothorax as a complication of combination antiangiogenic therapy in children and young adults with refractory/recurrent solid tumors. J Pediatr Surg. 2015:50:1484-9.

25. Crabb SJ, Patsios D, Sauerbrei E, et al. Tumor cavitation: impact on objective response evaluation in trials of angiogenesis inhibitors in non-small-cell lung cancer. J Clin Oncol. 2009;27:404-10.

26. Marom EM, Martinez $\mathrm{CH}$, Truong MT, et al. Tumor cavitation during therapy with antiangiogenesis agents in patients with lung cancer. J Thorac Oncol. 2008:3:351-7.

27. Motzer RJ, Escudier B, Oudard S, et al. Efficacy of everolimus in advanced renal cell carcinoma: a double-blind, randomised, placebo-controlled phase III trial. Lancet (London, England). 2008:372:449-56.

28. du Bois A, Floquet A, Kim JW, et al. Incorporation of pazopanib in maintenance therapy of ovarian cancer. J Clin Oncol. 2014;32:3374-82.

Ready to submit your research? Choose BMC and benefit from:

- fast, convenient online submission

- thorough peer review by experienced researchers in your field

- rapid publication on acceptance

- support for research data, including large and complex data types

- gold Open Access which fosters wider collaboration and increased citations

- maximum visibility for your research: over $100 \mathrm{M}$ website views per year

At $\mathrm{BMC}$, research is always in progress.

Learn more biomedcentral.com/submissions 